\title{
PECULIARITIES OF ZIGZAG BEHAVIOUR IN LINEAR MODELS OF SHIP YAW MOTION
}

\begin{abstract}
The present survey, as part of larger project, is devoted to properties of pure linear models of yaw motion for directionally stable ships, of the first- and second-order, sometimes referred to as the Nomoto models. In rather exhaustive way, it exactly compares and explains both models in that what is being lost in the zigzag behaviour, if the reduction to the simpler, first-order dynamics ( $K-T$ model) is attempted with the very famous [Nomoto et al., 1957] approximation: $T=T_{1}+T_{2}-T_{3}$. The latter three time constants of the second-order model, more physically sound, are strictly dependent on the hydrodynamic coefficients of an essential part of the background full-mission manoeuvring model. The approximation of real ship behaviour in either of the mentioned linearity orders, and the corresponding complex parameters may facilitate designing and evaluating ship steering, and identifying some regions of advanced nonlinear models, where linearisation is valid.

As a novel outcome of the conducted investigation, a huge inadequacy of such a first-order model for zigzag simulation is reported. If this procedure is used for determining steering quality indices, those would be of course inadequate, and the process of utilizing them (e.g. autopilot) inefficient.
\end{abstract}

\section{Keywords:}

zigzag test, ship manoeuvring, steering, Nomoto, linear model.

\section{INTRODUCTION}

The zigzag test is directly or indirectly a benchmark for evaluating ship performance. It combines both turning and course-keeping qualities required for navigation at open sea, that also essentially contribute to ship manoeuvrability in 
restricted area. Ships are obliged under IMO (International Maritime Organisation) to undergo this test and its data are often available onboard, besides various model-scale data, in terms of the heading time-history or the overshoot angles. Therefore, from the ship manoeuvring simulator developer's viewpoint, the zigzag data are extensively used to calibrate and evaluate the simulator mathematical models of ship motion.

For a given real ship, adjusting complex multi-DOF ship hydrodynamic models in full-mission manoeuvring simulators is a great challenge and requires an exact knowledge of the motion response sensitivity to model parameters. Under some assumptions, such models can be reduced to simpler 1-DOF models, more or less linear (or nonlinear), that enable rather clear insight into the zigzag performance and the responsible hydrodynamic model parameters. Of course, linear dynamic models of ship yaw motion have many applications in other fields, e.g. in ship design and steering control. They are recognised for simplicity, analytical solution, efficiency and validity under some conditions. However, they possess some disadvantages too, that sometimes should be assigned more to a procedure of determining its parameters than to the model structure itself.

[Sutulo, Guedes Soares, 2005], though finally concerned with nonlinear extensions of linear models, report on losing too much information if first-order linear models are used in zigzag simulation, however, without providing details of this statement. [Piegat, 1994] and many others within control engineering area consider classical inertial element of first- and second-order, that are really homogenous (left-hand side) parts of ship steering linear ODEs. Problems with specific $T_{3}$ constant in the right-hand side control input function of the ship second-order ODE are studied mostly deeply by [Norrbin, 1966]. However, none of the listed herein and some other authors have not raised the problem of certain inadequacy of the model order reduction proposed in [Nomoto et al., 1957].

The main objective of this paper is to compare the performance of firstand second-order linear models with respect to zigzag manoeuvring test, which case is rarely undertaken in literature.

\section{BASIC FORMULAS}

Let us assume the following standard, linear, fully dimensionless motion equations in 2DOFs (drift and yaw) for ship mild manoeuvres under constant forward speed: 


$$
\left\{\begin{array}{c}
\frac{d \beta}{d s^{\prime}}=a_{1} \beta+b_{1} \omega_{z}^{\prime}+c_{1} \delta \\
\frac{d \omega_{z}^{\prime}}{d s^{\prime}}=a_{2} \beta+b_{2} \omega_{z}^{\prime}+c_{2} \delta
\end{array},\right.
$$

where:

$a_{1}, b_{1}, c_{1}, a_{2}, b_{2}, c_{2}$ - constant hydrodynamic coefficients.

All these coefficients (parameters) combine contributions from hull and rudder, of course, each one in different way. Besides that, $b_{1}$ has very important component of centrifugal force. The dependent variables $\beta$ and $\omega_{z}^{\prime}$ represent the unknown motion parameters, the drift angle and dimensionless yaw velocity, respectively, while $\delta$ denotes the helm angle, i.e. the control input. The independent variable $s^{\prime}$ means dimensionless distance, or time, in that dimensional (absolute) distance $s$, or time $t$, is related to the movement of one ship length:

$$
d s^{\prime}=\frac{d s}{L}=d t \frac{v}{L}=\frac{d t}{t_{L}},
$$

where:

$L$ - ship length (between perpendiculars),

$v$ - ship speed,

$t_{L}$ — time of travelling ship length $(=L / v)$.

Since the zigzag manoeuvre is focused on getting heading information $\psi$, likewise all nautical manoeuvres, and additionally controlled by heading, we need to provide additional kinematical relationships:

$$
\frac{d \psi}{d t}=\omega_{z}, \quad \omega_{z}^{\prime}=\omega_{z} \frac{L}{v} \quad \Rightarrow \quad \frac{d \psi}{d s^{\prime}}=\omega_{z}^{\prime}
$$

where:

$\omega_{z}$ - yaw velocity.

The coupled differential equations (1) can easily be transformed to the well-known uncoupled second-order linear equation of yaw motion, of primary 
interest in the paper, and traditionally referred to as the second-order Nomoto model (briefly called hereafter '2nd-order model'):

$$
T_{1} T_{2} \frac{d^{2} \omega_{z}^{\prime}}{d s^{\prime 2}}+\left(T_{1}+T_{2}\right) \frac{d \omega_{z}^{\prime}}{d s^{\prime}}+\omega_{z}^{\prime}=K\left(\delta+T_{3} \frac{d \delta}{d s^{\prime}}\right),
$$

where:

$T_{1}, T_{2}, T_{3}-$ (dimensionless) time constants,

$K \quad$ - amplification (gain) constant.

An identical equation, of course, can be constructed for drift angle, where $K$ and $T_{3}$ will only change their definition. For directionally stable ship, in which case the model is able to predict, all listed time constants are positive. The appearance of $T_{3}$ in (4) is a direct outcome of drift-to-yaw coupling in (1), but some of this coupling also exists in other constants. The 2 nd-order equation (4) is such that we have 'its symmetry' against $T_{1}$ and $T_{2}$ values. It means, if we replace the both time constants each other, the equation is still identical. The usual definition (or selection) of $T_{1}$ and $T_{2}$ is such, that $T_{1}>T_{2}$.

We shall now introduce the first-order Nomoto model of simpler linearity:

$$
T \frac{d \omega_{z}^{\prime}}{d s^{\prime}}+\omega_{z}^{\prime}=K \delta
$$

for which the following approximation criterion, based on the time delay in heading asymptotic response to the step helm, is proposed and validated in the classical work of [Nomoto et al., 1957]:

$$
T=T_{1}+T_{2}-T_{3}
$$

The constant $K$ in (5) is identical to (4). For the purpose of present investigation, equation (5), combined essentially with (6), will be called the ' 1 st-order model'. The expression (6), expected to provide a good reduction of 2 nd- to 1 st-order dynamics, is widely used and quoted in the literature till the modern times, however, without presenting new results on zigzag performance, especially those less promising. 


\section{NUMERICAL STUDY — ASSUMPTIONS}

The following reference values are used in the subsequent numerical calculations:

2nd-order model, see (4):

$$
K=4.8958, \quad T_{1}=10.4909, \quad T_{2}=0.2981, \quad T_{3}=0.9832 ;
$$

1st-order model, see $(5,6)$ :

$$
K=4.8958, \quad T=9.8058 .
$$

The above values are concerned with a small chemical tanker, of ca. $100 \mathrm{~m}$ in length, based on theoretical (empirical) hydrodynamic coefficients, and calibrated next against sea trials.

A method applied to solve the equations of both linear models is the numerical integration of ODE using Euler scheme with the time step $\Delta s^{\prime}=0.002$. For the 1st-order model (5), the step 0.02 or little more (even as much as 0.1 ) may also be here sufficient to maintain visually identical zigzag results. The higher values of time step for both models, however, have not been challenged in detail and ultimately decided. The numerical optimisation is not considered a priority in the present piece of research. While assuming the relatively very low step 0.002, it was just attempted to avoid any potential numerical inaccuracies with some calculation conditions. It shall also be mentioned, that for the original set of two first-order ODEs (1), the required time step naturally gets closer to the value specific for the first-order uncoupled equation (5).

Although analytical solutions can also be derived for our linear equations, consisting of some exponential terms, this is impractical and would require dividing the zigzag heading curve and the helm curve into some regions. The resulting multiple-nested series of elementary contributions to the response, for a few counter-helms, is very long and complicated to study it. The fundamental formulas for elementary trapezoidal helm input can be independently derived by the reader or found in many references. In the latter case, e.g. [Nomoto et al., 1957], [Clarke et al., 1983], they rather refer to zero initial conditions, and are affected by some minor errors.

The helm speed adopted in the calculations, in absolute magnitude, corresponds to the SOLAS requirement, that is $2.3 \%$ s for one steering gear motor 
running (of two), and abt. $5 \%$ for two motors in action. In our equations, taking into account the possible range of ship length and speed, this dimensional helm speed is recalculated according to similarity law, i.e. multiplied by the $t_{L}=L / V$ factor, see (2), thus leading to two extreme reference cases of dimensionless helm speed:

- $2.3 \%$ and $L=100 \mathrm{~m}, V=10 \mathrm{~m} / \mathrm{s}\left(t_{L}=10 \mathrm{~s}\right)$, that resolves to $d \delta / d s^{\prime}=23 \% / L$;

- $5 \% \mathrm{~s}$ and $L=300 \mathrm{~m}, V=5 \mathrm{~m} / \mathrm{s}\left(t_{L}=60 \mathrm{~s}\right)$, that gives round $d \delta / d s^{\prime}=300 \% L$.

Hereafter in the paper, whenever we refer to 'zigzag', we mean exactly its type $10^{\circ} / 10^{\circ}$, that is constituting a basis of the present investigation. Although some results are valid for some other types of zigzag tests, especially more or less harder, this rather mild $10^{\circ} / 10^{\circ}$ version seems mostly suitable from the viewpoint of assumed linearity to the dynamic model and great popularity among researchers. The latter is connected with huge availability of published theoretical or experimental records of zigzag tests, that enables further comparison and study of the problem.

\section{NUMERICAL STUDY — BASIC RESULTS}

Below and in the next chapter are presented the most important properties of the both linear models as numerically simulated with the above assumptions.

In Figure 1, one can notice the claimed divergence of both models and the impact of helm speed in the zigzag performance. For legibility, the helm curve (dashed line) in Figures 1 and 2 is presented only for the 2nd-order model. The 2nd-order (hydrodynamically sound) model provides much lower overshoot angles. The trend with the helm speed is similar for the both models, e.g. with respect to the overshoot angles that increase roughly by $5^{\circ}$ (1st overshoot) and $10^{\circ}$ (2nd overshoot) with the slower helm. Due to larger overshoot angles, also the zigzag period is likely increased. Recapitulating, the both models are affected by the helm speed in the same way, thus maintaining their initial difference. In other words, $T_{3}$ in the 2 nd-order model acts similarly independent of the helm speed. The examined range of dimensionless helm speed, where the upper and lower values differ as much as more than 10 times, seems extreme yet real. For an individual ship (of 'constant' length) the range of helm speed will be, of course, much lower. In the case of larger and slower ships, with two motors engaged of 
the steering gear, the helm absolute speed in $\% \mathrm{~s}$ is almost insignificant, if compared to a ship's movement. Thus, it can be treated more as rapid (step) helm. Surprisingly, the both models also respond similarly in this case.

Although not directly connected with the present paper's interest, the ships with high length-to-speed ratio $(L / V)$, see Figure 1, 'hydrodynamically' reveal lower overshoot angles. In the IMO requirements, however, higher overshoot angles are allowed. As is known, the latter are introduced more from the human response point of view than from the hydrodynamic point of view.

HELM $23 \% / L$

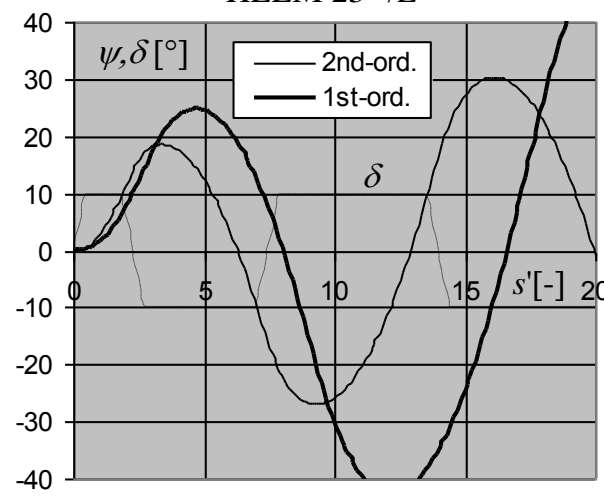

HELM $300 \% / L$

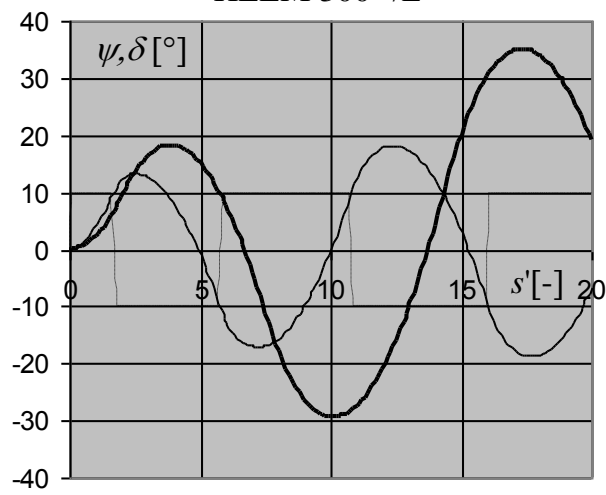

Fig. 1. Zigzag heading history for 1st and 2nd-order linear models

The same trends, proving the definitive incompatibility of 1st- and 2nd-order models in some (maybe, in many) rather usual conditions, while simulating the zigzag manoeuvre, can surprisingly be also furnished for the very popular Mariner ship studied in [Tzeng, Chen, 1999] and in many other works, that is:

$$
K=0.185 \mathrm{~s}^{-1}, T_{1}=118 \mathrm{~s}, T_{2}=7.8 \mathrm{~s}, T_{3}=18.5 \mathrm{~s} ; \quad T=107.3 \mathrm{~s} .
$$

This has also been checked by this author and can be verified even by the reader. The literature has not reported this fact at all so far. Disregarding the dimensional definition of (8), that is not important, the mutual configuration of values in (8) is similar to (7). It must be stressed, however, that this statement is valid for the inextricable approximation criterion given in (6), leading to $T=107.3 \mathrm{~s}$ with the preserved $K$ value.

If $K$ and $T$ of a first-order model are 'globally' indentified from the zigzag curve of 2nd-order model, using e.g. the procedure of [Nomoto, 1960] or the quite 
different least-square fitting, the agreement between the models would be much improved. The $K$ and $T$ values obtained this way would obviously have different meaning and violated relevance to the hydrodynamics reflected in (1). To exemplify such a new situation, this author has used the famous [Nomoto, 1960] method to 'identify' $K$ and $T$ from the simulated 2nd-order response in Figure 1 (left $23^{\circ} / L$ ). The original values, see (8) [Nomoto et al., 1957], are ca. 4.90 and 9.81 accordingly. The new values, based on the first half-period (full-period) decrease (!) down to $K=1.94$ (2.17) and $T=3.09$ (3.61), giving $\underline{2.06}$ and $\underline{3.35}$ on average. The simulation of the first-order model with the latter, average constants is demonstrated in Figure 2 ('1st-ord. NEW') together with the previous results.

HELM $23 \% / L$

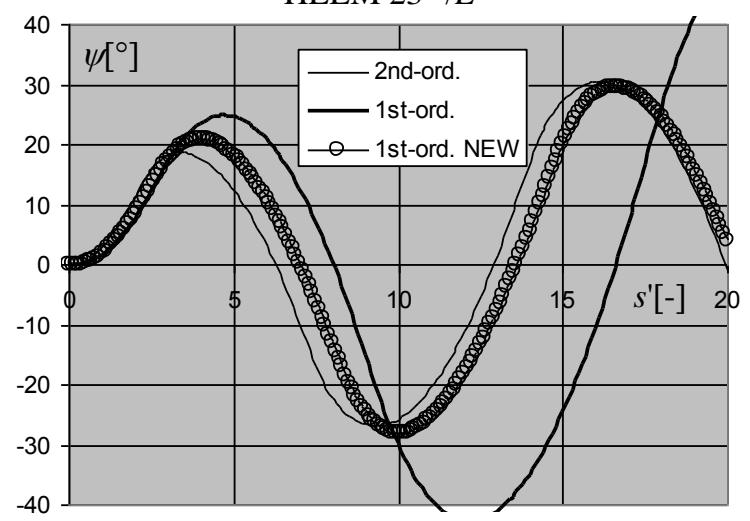

Fig. 2. Performance of 1 st-order model with $K$ and $T$ as 'globally' identified

Figure 3 presents the time history of dimensionless rate of turn (yaw velocity) and its derivative. The cause of different behaviour in zigzag for the both models is best depicted in the plot of yaw acceleration (due to differential nature and thus sensitiveness of this presentation). Particularly, see the jumps for the 2nd- order model that are essentially 'damped' by the 1st-order model. The 2nd-order model gives more rapid response, either to initiate or to check the heading alteration, leading to much lower overshoot angles.

Figure 4 (the helm speed case $23 \% / L$ only) provides another illustration of the divergence of both models, this time in the form of the so-called phase diagrams, very useful in studying internal relationships in the model and in the identification of its parameters. The 1st-order model presents itself most clearly in the lower chart of this figure (yaw acceleration vs. velocity), where it assumes an almost perfect inclined rectangular shape. 


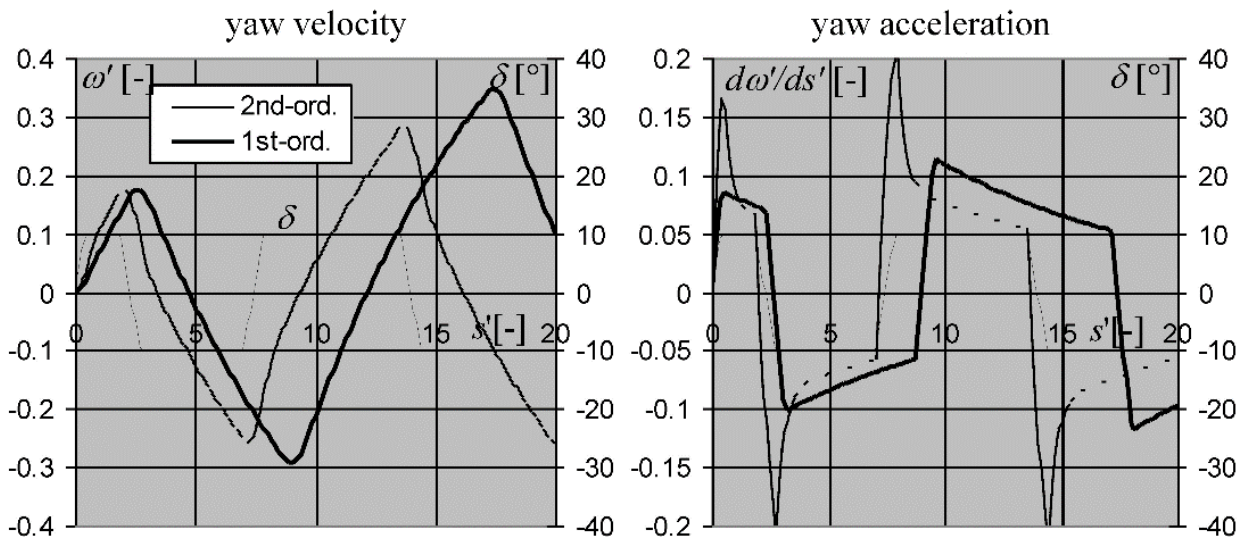

Fig. 3. Dimensionless yaw velocity and acceleration for the case $23 \% / L$
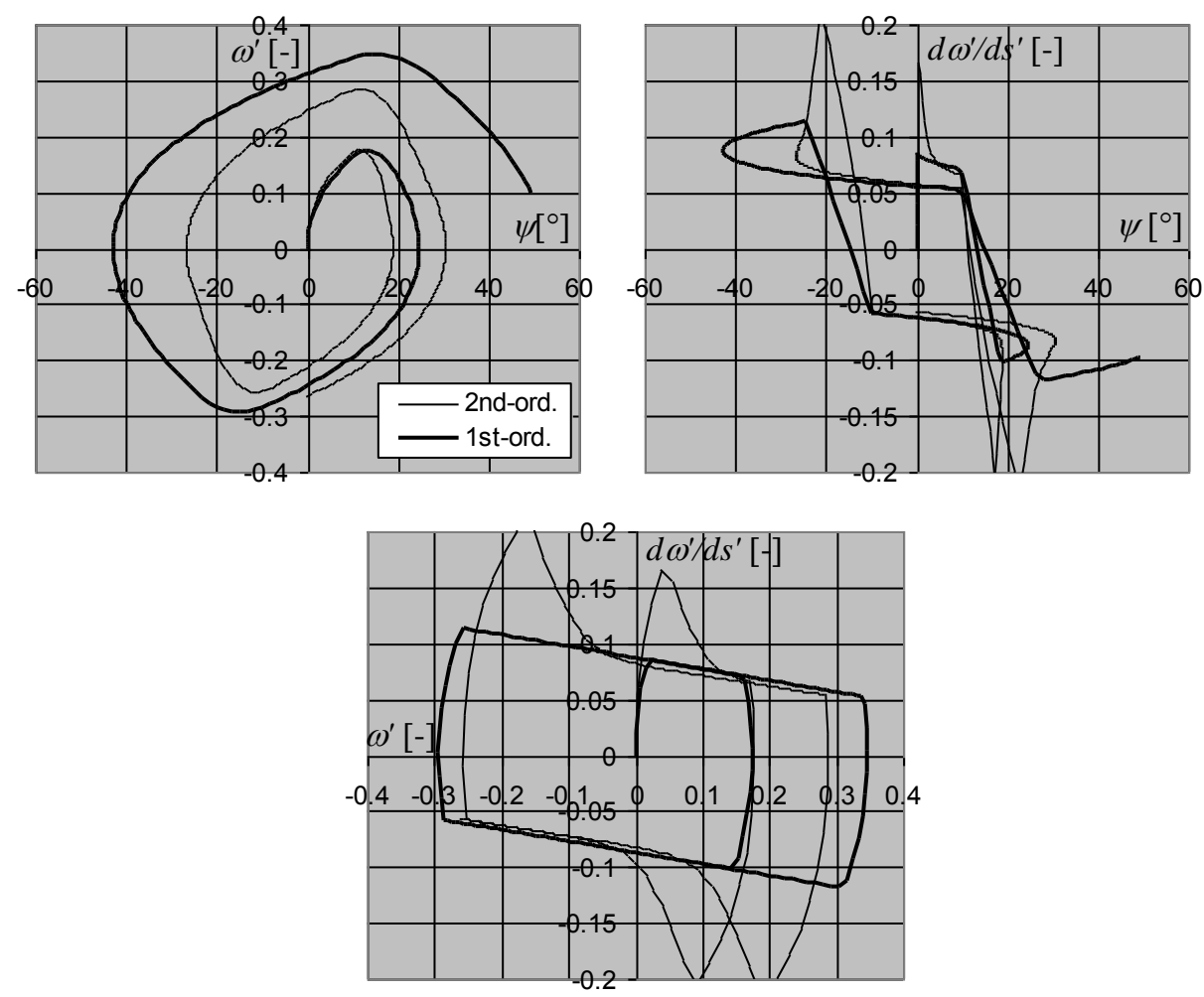

Fig. 4. Various phase diagrams for the case $23 \% / L$ 


\section{NUMERICAL STUDY — FURTHER (SENSITIVITY) RESULTS}

In Figure 5 there is displayed a situation, when $T_{3}$ constant is forced to zero, while all other constants in (7) are preserved. The constant $T$ of the 1st-order model is updated accordingly to (6). The helm curves in this (and subsequent figures) are already omitted. It can now be concluded that the differences in the models lie in the second derivative of yaw velocity and are connected with the both time constants $T_{1}$ and $T_{2}$. The role played by $T_{3}$ constant, compare Figure 5 to Figure 1 , is also very crucial. However, unlikely in Figure 1, the helm speed $d \delta / d s^{\prime}$ in (4) is disappearing (due to $T_{3}=0$ ), but is still used indirectly in the variation of helm angle with time under the function $\delta=\delta\left(s^{\prime}\right)$, leading again to lower overshoot angles with faster helm.

There is no mistake in this Figure 5 - the differences between the both models, though less conspicuous, are now inverted, in that a little higher overshoot angles are exhibited by the 2 nd-order model. $T_{2}$, roughly equal 0.3 , i.e. much lower than $T_{1}$, is yet of significant magnitude as to introduce some differences between the both models.

HELM $23 \% / L$

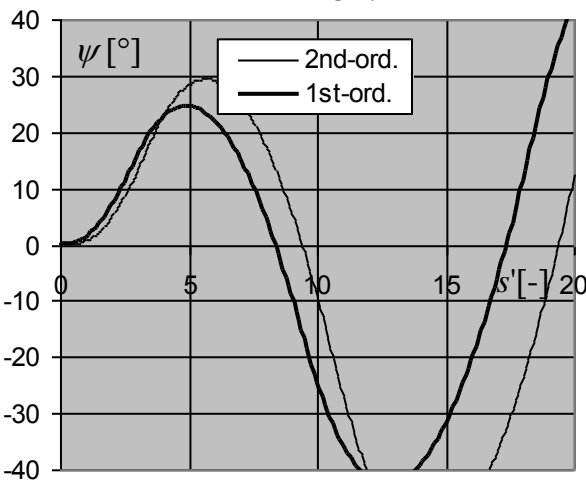

$\operatorname{HELM} 300^{\circ} / L$

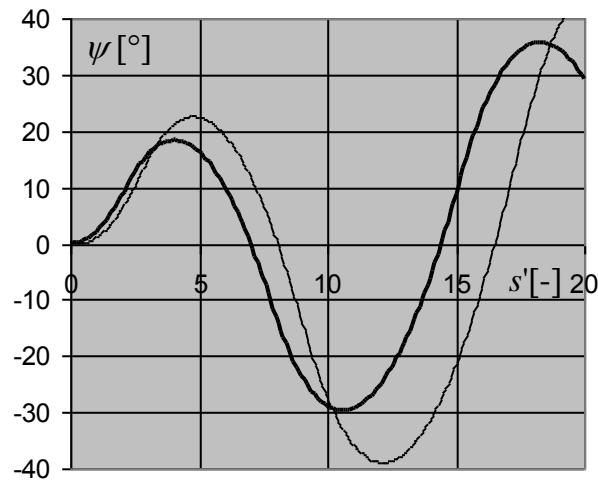

Fig. 5. $T_{3}=0$ situation for various helm speed (differences between models are reverted)

Figure 6 shows the effect of rather mild increase of $T_{2}$, from $\sim 0.3$ to 1.0 , under the previous assumption of $T_{3}=0$ (the case of $23^{\circ} / L$ only). Compare this result with the left diagram of Figure 5. The zigzag performance in the 2nd-order model, in contrast to the 1 st-order model, is very sensitive to $T_{2}$. On the other extreme, if $T_{2}$ is reduced up to a very low value, e.g. less than $0.01\left(10^{3}\right.$ times 
lower than $T_{1}$ ), the both models practically coincide with each other, that is not shown in the paper. By additional simulations, it is also found out that 2nd-order model performance quoted in this paragraph is not bound by $T_{3}=0$, but practically by the positive difference $T_{2}-T_{3}\left(T_{2}>T_{3}\right)$, that is hardly, however, the case in ship hydrodynamics.

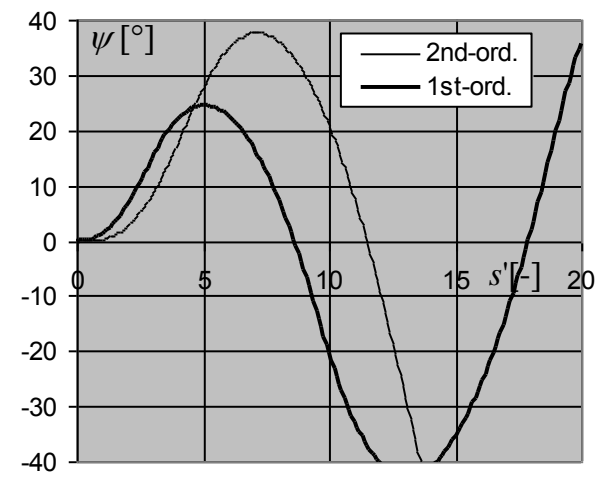

Fig. 6. $T_{3}=0$ situation for helm $23^{\circ} / L$ and forcing $T_{2} \rightarrow 1.0$

Figure 7 presents the most interesting case, that will receive special attention in next chapters - the zigzag coincidence of the both models for $T_{3}=T_{2}$ (in which case $T=T_{1}$ ). Such a behaviour is completely independent of $T_{2}$ magnitude.

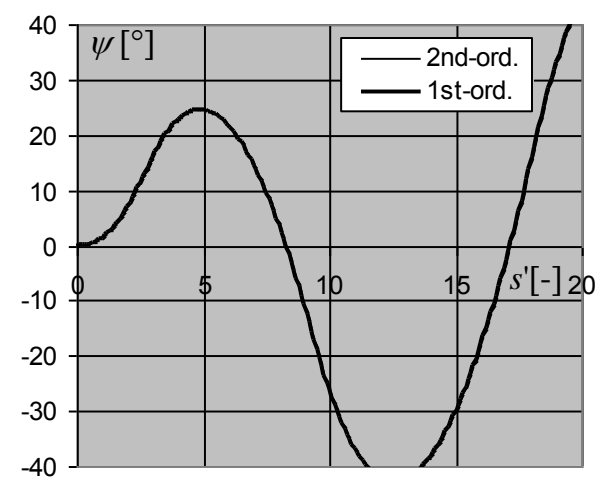

Fig. 7. $T_{2}=T_{3}$ situation for helm $23^{\circ} / L$ (identical for arbitrary $T_{2}$ ) 


\section{PROOFS OF CONDITIONS $\left(T_{3}=T_{2} \Rightarrow T=T_{1}\right)$ FOR EXACT 2ND- TO 1ST-ORDER MODEL CONVERGENCE}

To explain the behaviour found for the 2nd-order model with the forced equality $T_{3}=T_{2}$, Figure 7 , signifying the true reduction of the linearity order up to the first order, we may revert to the frequency (spectral) characteristics of the second-order system as analytically presented e.g. in [Nomoto et al., 1957, p. 359]. Those are defined in terms of amplitude ratio and phase lag of yaw versus harmonic steering. The response goes simple, being then solely a function of $T_{1}$, if we just insert $T_{3}=T_{2}$ into the quoted formulas. The same, but even more elegantly, is reached when we examine the Laplace transform definition of transfer function for this system [Nomoto et al., 1957, p. 360, 3rd equation from top]:

$$
\frac{\omega_{z}^{\prime}(p)}{\delta(p)}=\frac{K\left(1+T_{3} p\right)}{\left(1+T_{1} p\right)\left(1+T_{2} p\right)}
$$

in that corresponding factors in the numerator and denominator completely cancel each other.

However, either the frequency characteristics (Fourier transform-based) or its fully equivalent Laplace transform-defined transfer function describe the system response to (steering) input in limited, partial way. Namely, either the steady-state response or zero initial conditions (with regard to yaw velocity and acceleration) are considered accordingly. However, since the zigzag normally starts at zero initial conditions, using the transfer function (10) with its underlying assumptions, we are able to say that up to the first counter-helm the both 1st- and 2nd-order models would identically evolve. This is also clear and trivial when we investigate the Laplace transform-defined full response at arbitrary initial conditions, i.e. comprising the so-called (transient) memory effect, wherein only $T_{1}$ and $T_{2}$ nominally stand, that is derived in [Nomoto et al., 1957, p. 360, 1st \& 2nd equation from top]. However, for non-zero initial conditions, as present at the first and subsequent counter-helms, the numerically observed reduction of the response to the 1st-order (with $T_{1}$ only) is not obvious within this memory-effect term, where we need $T_{2}$ to disappear. The key to success should lie in deriving and substituting zigzag-specific initial conditions to this memory effect, which are functions of $T_{1}$ to $T_{3}$. It is believed this should be little challenge in the future. 
Another support is rendered by time-based response for elementary trapezoidal steering, which is rather easy for development, even under non-zero initial conditions. Under zero initial conditions, we may directly refer to [Clarke et al., 1983, eq. (12)], that has less minor errors than [Nomoto et al., 1957]. Up to the first counter-helm, only the term with $T_{1}$ is left if we take advantage of $T_{3}=T_{2}$. The formal analytical proof of the heading behaviour at further advance of time will remain unsolved in this paper, expecting no trouble to do it. The full analytical proof is much better than numerical (performed in the paper), since among others it directly identifies the structure of the analysed system.

In fact, it is worthwhile to recall (4) under the specific conditions of $T_{3}=T_{2}$ that yields a specific and intriguing equation:

$$
T_{1} T_{2} \frac{d^{2} \omega_{z}^{\prime}}{d s^{\prime 2}}+\left(T_{1}+T_{2}\right) \frac{d \omega_{z}^{\prime}}{d s^{\prime}}+\omega_{z}^{\prime}=K\left(\delta+\underline{T_{2}} \frac{d \delta}{d s^{\prime}}\right)
$$

that is surprisingly independent of $T_{2}$, at least for the zigzag test, and actually denotes the fully first-order linearity of response as described before.

Another matter is whether the so-called cancellation effect, studied e.g. by [Hwang, 1982], [Holzhuter, 1990], being a correlation between dependent variables that impede model identification, also referred to as the ill-posed problem, can be linked to the cancellation of $T_{2^{-}}$and $T_{3}$-terms in the transfer function (10). The answer is obviously true, particularly in view of [Tzeng, Chen, 1999]. However, it is rarely to note that with $T_{3} \approx T_{2}$ we essentially get a first-order linear dynamics, that cannot be identified with the specific second-order model of the form (4). In other words, this instance of second-order model cannot be naturally reduced to or easily 'encompass' the first-order dynamics unless some asymptotic behaviour is considered. Namely, it inherently possesses hard 'second-order' properties, which cannot be disregarded.

It had not been reported in the original work of [Nomoto et al., 1957], by far the most informative source, and in later and recent references, how close to $T_{2}$ we should keep $T_{3}$ to get reasonable 'identity' of the both 1 st- and 2 nd-order models in the zigzag simulation. In other words, how the 2nd-order model is sensitive on these two time constants, because their order of magnitude vs. $T_{1}$ is not so important, if $T_{3} \approx T_{2}$, as someone may believe. 


\section{$T_{2}$ AND $T_{3}$ EQUALITY IN HYDRODYNAMIC TERMS}

Based on the hydrodynamic coefficients of the background set of linear equations (1), $T_{2}$ and $T_{3}$ in (4) classically read as follows:

$$
\begin{gathered}
T_{2}=-\frac{1}{0.5\left(a_{1}+b_{2}-\sqrt{\left(a_{1}+b_{2}\right)^{2}-4\left(a_{1} b_{2}-a_{2} b_{1}\right)}\right)} \\
T_{3}=\frac{c_{2}}{-a_{1} c_{2}+a_{2} c_{1}} .
\end{gathered}
$$

Making them equal, one finally gets the hydrodynamic condition of the linear dynamics convergence from the 2nd- to 1st-order:

$$
b_{1}=\frac{c_{1}}{c_{2}}\left(-a_{1}+b_{2}+a_{2} \frac{c_{1}}{c_{2}}\right)
$$

that is essentially based on the ratio $c_{1} / c_{2}$. This factor is a function of dimensionless gyration radius of ship, her added mass dimensionless coefficients for sway and yaw, and the 'effective' (sometimes different than geometrical) rudder location. We can next transform this simple (!) equation to get an explicit formula for the particular hydrodynamic coefficient, if all the other quantities are known.

\section{CONCLUSIONS}

In the paper, problems with the first-order approximation applied to the background, hydrodynamics-related, second-order linear response in ship yaw have been studied and diagnosed.

Adopting the frequently quoted time constant reduction criterion (6), with the preserved gain constant, exactly consists in assuming $T_{2}=T_{3}$. This leads to a drastic change of the response in zigzag manoeuvre. The relative magnitudes of three time constants in the second-order equation is not so important, as one may expect. For many second-order model instances, as published, this approximation is unacceptable, at least as far as we simulate the zigzag test and are interested in its overshoot angles and periods. However, the same incompatibility may affect other types of steering. 
If $K$ and $T$ constants for the first-order model are provided, they should always be asked for methodology. If they are based on various techniques of model fitting to recorded sea trial data, the first-order model can well simulate the zigzag manoeuvre, but it certainly loses, confuses or changes the hydrodynamic sense. Therefore, such first-order model constants cannot be directly converted to relationships between the hydrodynamic coefficients in a full-mission model.

Summarising, it is thus encouraged to start in the future a development of procedure to identify the four-parameter second-order model from the zigzag test records.

\section{Acknowledgements}

This publication has been partly financed from a subsidy of the Ministry of Science and Higher Education (Poland) for statutory activities of the Szczecin Maritime University, Faculty of Navigation under the research project No. 1/S/CIRM/16.

\section{REFERENCES}

[1] Clarke D. et al., The Application of Manoeuvring Criteria in Hull Design Using Linear Theory, 'RINA Trans.', 1983, Vol. 125.

[2] Holzhuter T., A workable dynamic model for the track control of ships, Ninth Ship Control Systems Symposium. Proceedings, Sep. 24-27, Vol. 4, Bethesda 1990.

[3] Hwang W. Y., Cancellation Effect and Parameter Identifiability of Ship Steering Dynamics, 'International Shipbuilding Progress' (ISP), 1982, Vol. 29, No. 332.

[4] Nomoto K., Analysis of Kempf's standard maneuver test and proposed steering quality indices, First Symposium on Ship Maneuverability, May 24-25, DTMB Rep. 1461 (AD 442036), Washington 1960.

[5] Nomoto K. et al., On the Steering Qualities of Ships, 'International Shipbuilding Progress', 1957, Vol. 4, No. 35.

[6] Norrbin N. H., Further Notes on the Dynamic Stability Parameter and the Prediction of Manoeuvring Characteristics, MARSIM '96 Proc., Marine Simulation and Ship Manoeuvrability (A. A. Balkema, Rotterdam), ed. M. S. Chislett, Sep 9-13, DMI, Copenhagen 1996.

[7] Piegat A., Introduction to Control Engineering, Technical University, Szczecin 1994 [in Polish].

[8] Sutulo S., Guedes Soares C., Numerical Study of Some Properties of Generic Mathematical Models of Directionally Unstable Ships, 'Ocean Engineering', 2005, Vol. 32, pp. 485-497. 
[9] Tzeng C. Y., Chen J. F., Fundamental Properties of Linear Ship Steering Dynamic Models, 'Journal of Marine Science and Technology' (NTOU), 1999, Vol. 7, No. 2.

Received September 2016

Reviewed November 2016

\author{
JAROSLAW ARTYSZUK \\ Maritime University of Szczecin \\ Wały Chrobrego 1 Str., 70-500 Szczecin, Poland \\ e-mail: j.artyszuk@am.szczecin.pl
}

\title{
STRESZCZENIE
}

W artykule przedstawiono analizę krytyczną konsekwencji upraszczania równania liniowego Nomoto drugiego rzędu prędkości kątowej statku do postaci pierwszego rzędu z punktu widzenia symulacji próby wężowej. Stwierdzono nieadekwatność (niezgodność z pierwotnym zachowaniem) zredukowanego modelu przy zastosowaniu klasycznych kryteriów [Nomoto et al., 1957].

Model drugiego rzędu (4-parametrowy) prędkości kątowej bezpośrednio wynika z elementarnego układu dwóch sprzężonych liniowych równań róźniczkowych prędkości kątowej i kąta dryfu — zmiennych opisujących podstawowe ruchy manewrowe statku. Choć dziedziczy ścisłe podstawy hydrodynamiczne, model drugiego rzędu jest wciąż trudny do identyfikacji w oparciu o proste próby manewrowe, m.in. wspomnianą próbę wężową. Tym samym również jego zastosowanie w projektowaniu (manewrowym) statku, okrętowych systemów sterowania, np. autopilotów, i w ocenie właściwości manewrowych statku jest jak na razie ograniczone. Zupełnie odmiennie przedstawia się sytuacja dla modelu pierwszego rzędu (2-parametrowego, tzw. $K-T$ ). Model ten jest bardzo popularny i łatwo identyfikowalny. Jednakże jeśli parametry modelu pierwszego rzędu zostały wyznaczone według próby wężowej, to nie można ich wykorzystać w identyfikacji powyższego bazowego układu równań. Z kolei jeśli parametry te zostały określone na podstawie parametrów modelu drugiego rzędu ( współczynników hydrodynamicznych równań) przy użyciu krytykowanej metody redukcji, to model pierwszego rzędu nie zapewnia adekwatnej symulacji próby wężowej, co ogranicza niektóre jego zastosowania. 